\title{
An assay for the analysis of lymphocyte migration across cerebral endothelium in vitro
}

\author{
Gareth Pryce, Washington Santos and David Male * \\ Department of Neuropathology, Institute of Psychiatry, De Crespigny Park, London SE5 8AF, UK
}

(Received 16 December 1992, revised received 9 July 1993, accepted 3 August 1993)

We describe a recently developed assay for the analysis of leukocyte migration across cerebral endothelium in vitro. The endothelium is grown as monolayers on Goretex or Cyclopore membranes coated with extracellular matrix proteins and supported on inserts. This system permits the recovery and phenotyping of cells which migrate down through the endothelium. Using labelled lymphocytes we were able to differentiate four populations of cells, with differing degrees of mobility in the migration assay. We have compared the results from this system with those from conventional adhesion assays. Binding of cells to the endothelium is rapid, but is confined to a particular subpopulation of the applied lymphocytes. We have followed cell migration over $24 \mathrm{~h}$ in the system using normal and cytokine-activated endothelium and have found that whereas adhesion depends both on the state of lymphocyte activation and on the condition of the endothelium, the level of migration of stimulated lymphocytes is largely independent of endothelial activation. Moreover, whereas CD $8^{+}$cells bind well to the endothelium, it is the $\mathrm{CD}^{+}$cells which migrate most effectively. Comparison of brain and epididymal fat endothelium showed similar migration levels over $2 \mathrm{~h}$, but migration was greater across epididymal fat endothelium at $24 \mathrm{~h}$.

Key words: Endothelium; Lymphocyte; Migration; Adhesion

\section{Introduction}

Lymphocyte migration across cerebral vascular endothelium is a central event in the initiation and development of immune responses in the brain. The level of cell migration into brain is normally very low in comparison with other tissues, although this is greatly increased when in-

\footnotetext{
* Corresponding author. Fax: 0717083895.

Abbreviations: BSS, Hanks' balanced salts solution; ConA, concanavalin A; EAE, experimental allergic encephalomyelitis; EM, electron microscopy; FCS, foetal calf serum; IFN- $\gamma$, interferon- $\gamma$; PDS, plasma derived serum; TNF- $\alpha$, tumour necrosis factor $\alpha$.
}

flammatory reactions do develop. This control on leukocyte migration has been attributed to the highly specialised nature of the cerebral endothelium (Male, 1992).

The first event in cell migration is the attachment of lymphocytes to the cerebral endothelium, particularly in venules, where haemodynamic shear and endothelial surface charge are both low (Vorbrodt et al., 1990). Lymphocytes then move across the endothelium towards the junctions between the endothelial cells, and pseudopodia probe the region around the junctions (Wisniewski and Lossinsky, 1991).

In previous experiments we have examined the factors which control the initial adhesion between 
lymphocytes and endothelium using rat cerebral endothelial cells in vitro. Two principle factors were found to control this interaction: (1) the state of endothelial cell activation, which can be modulated by cytokines, including TNF- $\alpha$ and IFN- $\gamma$ and (2) the state of activation of the lymphocytes, inducible by mitogens or their specific antigen (Male et al., 1990; Wekerle et al., 1991).

In this study we describe a new transendothelial migration system, which has allowed us to measure not just those cells which bind to the endothelium, but also the population which traverses it. We present data on the kinetics of trans-endothelial migration and on the phenotype of the migrating cells using antibodies to CD4, CD8 and CD2. Comparison of these results with those obtained from the adhesion assays (Pryce et al., 1991) shows a number of interesting differences. For example, CD8 cells bind at least as effectively as CD4 cells but migrate much less well. Also we have noticed that whereas both the state of the endothelium and the level of lymphocyte activation control adhesion, cytokine activation of the endothelium has little effect on the migration of dividing cells. This assay will be valuable in differentiating those factors which control cell migration, from those which are involved in the initial attachment of the lymphocytes to the brain endothelium.

\section{Materials and methods}

\section{Endothelium}

Brain microvascular endothelium was isolated from 2-3-month-old female Lewis rats according to methods described previously (Male et al., 1987). Briefly, cerebral cortices were dissected from two female 2-3-month-old Lewis rats. After removal of the meninges and white matter the tissue was chopped and digested with collagenase/dispase (Boehringer) for $1 \mathrm{~h}$. The tissue was then homogenised by trituration and the myelin removed by resuspension and centrifugation in a $250 \mathrm{mg} / \mathrm{ml} \mathrm{BSA}$ solution. The resulting pellet was re-digested in collagenase/dispase for a further $3 \mathrm{~h}$ and the microvessel fragments recovered on a $50 \%$ Percoll gradient (Sigma). Microvessel fragments were seeded onto type I col- lagen-coated tissue culture flasks, and grown until close to confluence (6-9 days) in HAMS F10 medium containing $20 \%$ plasma derived serum (Bowman et al., 1983), $40 \mu \mathrm{g} / \mathrm{ml}$ heparin, 75 $\mu \mathrm{g} / \mathrm{ml}$ endothelial cell growth supplement (Sigma), $100 \mathrm{U} / \mathrm{ml}$ penicillin, $100 \mu \mathrm{g} / \mathrm{ml}$ streptomycin and $5 \mu \mathrm{g} / \mathrm{ml}$ ascorbic acid. Previous studies have shown that these cells express Von Willebrand factor and the transferrin receptor (Hughes and Lantos, 1986).

Epididymal fat endothelium was isolated by dissecting the fat pad from the capsule of male Lewis rats. A piece of approximately $1 \mathrm{~cm}^{2}$ was finely chopped with scissors and digested for $1 \mathrm{~h}$ at $37^{\circ} \mathrm{C}$ in collagenase / dispase / DNAse / TLCK, as above. The digest was triturated and filtered through a sterile nylon mesh of $0.45 \mathrm{~mm}$. The filtered cell suspension was then washed and plated out on collagen-coated flasks, in endothelial cell growth medium, and grown on.

When near to confluence, the monolayers of either endothelial cell type were washed in BSS lacking $\mathrm{Ca}^{2+}$ and $\mathrm{Mg}^{2+}$ and then detached from the flask by treatment with $1 \mathrm{mg} / \mathrm{ml}$ trypsin (Sigma). After washing the primary cultures were then seeded onto the tissue culture inserts described below.

\section{Tissue culture system}

The tissue culture system was based on that previously described by Darby et al. (1988) for determining the migration of human monocytes across pig aortic endothelium. This uses hydrophilic Goretex membranes (W.L. Gore and associates, Dundee, Scotland) attached by MF cement (Millipore) to small inserts suspended in 24 well tissue culture plates. The assemblies were sterilised by soaking in $70 \%$ ethanol, air dried and washed repeatedly in BSS to remove traces of the adhesive solvent. We noted that cyanoacrylate based adhesives were toxic to the cells. The advantage of this system is that the membranes have large $(20 \mu \mathrm{M})$ pores which present no barrier to lymphocyte migration. However, we found that the system as described for pig large vessel endothelium, would not be satisfactory with rat cerebral microvessel endothelium, since the cells would neither attach to the membranes nor divide. To promote attachment of the endothelial 
cells we attempted to coat the membranes with combinations of laminin, fibronectin and collagen but none of these was found to be satisfactory. We eventually found that coating the membranes with $7.5 \mu$ l Matrigel (Collaborative Research) (a minimum volume) permitted attachment of the cells. However no cell outgrowth occurred under these conditions, and it was necessary to overlay the matrigel with $0.33 \mathrm{mg} / \mathrm{ml}$ type I collagen, fixed in ammonia vapour, as previously described (Male et al., 1987). The bottom of the 24 well plates was coated with collagen similarly. The inserts were then seeded with endothelium from primary cultures, and grown until confluent (2-4 days) in medium, as above, but with $10 \%$ foetal calf serum substituted for the plasma derived serum.

All the migration experiments described used Goretex membranes. However we later found that Cyclopore membranes, which are hydrophilic polycarbonate membranes porated using a $\mathrm{Cy}$ clotron (Medicell International) with $10 \mu \mathrm{M}$ pores could also be used. These are easier to handle than Goretex, and we found that it is possible to embed them and cut them in transverse section for transmission electron microscopy. In contrast, the Goretex membranes are supported on a mesh of nylon fibres which could not be cut easily.

The wells were checked for confluence by inverse light microscopy. This was easier with the cyclopore membranes due to their better optical properties. In addition the bottom of the culture wells was checked to see whether any endothelium had leaked through the membrane. Any chambers with incomplete monolayers, or with evidence of membrane leakage, were rejected. A typical primary culture from two rats provides sufficient brain endothelium to cover $16-24 \mathrm{mi}-$ gration chambers. Usually, a small number (0-4) could not be used due to lack of monolayer integrity.

When confluent, the cultures were pulsed for $16 \mathrm{~h}$ with cytokines, under conditions which we have previously shown to optimally enhance lymphocyte adhesion (Hughes et al., 1988); $50 \mathrm{ng} / \mathrm{ml}$ TNF- $\alpha$ (a generous gift of Dr. G. Adolf, Genentech), or $50 \mathrm{U} / \mathrm{ml}$ rat IFN- $\gamma$ (kindly supplied by Dr. P.H. van der Meide, Primate Research Centre, Rijswijk), or medium alone (control).
Lymphocytes were prepared from mixed syngeneic lymph nodes (cervical, brachial, inguinal, and mesenteric) and cultured overnight before use in RPMI containing $10 \%$ foetal calf serum, penicillin and streptomycin as above. These cells contained $54 \%(50-57 \%) \mathrm{CD}^{+}$cells, $24 \%$ (17$33 \%) \mathrm{CD}^{+}$cells and $29 \%(17-33 \%) \mathrm{B}$ cells, defined by surface Ig, or CD45R.ABC (the figures quoted are medians with ranges in brackets). In most experiments, these cells were preactivated by the addition of $5 \mu \mathrm{g} / \mathrm{ml}$ ConA for $16 \mathrm{~h}$, in cultures at $4 \times 10^{6}$ cells $/ \mathrm{ml}$.

In our initial experiments we labelled the lymphocytes by incubation in ${ }^{51} \mathrm{Cr}$ for $90 \mathrm{~min}$ suspended in protein-free BSS before the start of the migration assay (Hughes et al., 1988). However, we subsequently found that there was a considerable release of the label from the cells over the longer time periods of the migration assays (up to $24 \mathrm{~h}$ ). Furthermore, we found that the endothelial cell cultures maintained gradients of free ${ }^{51} \mathrm{Cr}$, possibly a reflection of their ability to maintain a blood brain barrier. These problems made it difficult to analyse assays using ${ }^{51} \mathrm{Cr}$. Subsequently we labelled cells with ${ }^{125}$ IUdR (1 $\mu \mathrm{Ci}$ per $10^{6}$ cells) for the duration of the overnight culture. This technique has the advantage of low non-specific release of label, but it means that the label is selectively distributed in actively dividing cells.

Both endothelium and lymphocytes were washed three times in BSS before the start of the migration assay. The lymphocytes were resuspended in RPMI containing $10 \%$ foetal calf serum and overlaid on the endothelium at $2 \times 10^{6}$ cells on an insert of surface area $0.64 \mathrm{~cm}^{2}$. The cultures were maintained at $37^{\circ} \mathrm{C}$ in $5 \% \quad \mathrm{CO}_{2}$ for periods up to $24 \mathrm{~h}$ before the degree of cell migration was assessed.

We differentiated four different cell populations from each migration well:

(1) unbound cells, removed from the top of the monolayers by washing in warm $\left(37^{\circ} \mathrm{C}\right) \mathrm{BSS}$;

(2) bound, non-migrating cells, removed from the monolayers by washing in cold $\left(4^{\circ} \mathrm{C}\right) \mathrm{Ca}^{2+} / \mathrm{Mg}^{2+}$ free BSS;

(3) migrating cells plus strongly adherent cells, assessed by lysing the tissue culture inserts in $2 \%$ SDS, and recovering the released label; 
(4) fully migratory cells, which migrated through the inserts and down to the bottom of the lower chamber. These cells were seen to be highly active and visibly motile under light microscopy on the collagen-coated surface of the lower chamber.

In these experiments, we were able to account for $80-90 \%$ of the applied radiolabel, distributed between cells in these four compartments. Recovery of ${ }^{51} \mathrm{Cr}$ in the cell fractions in the earlier experiments was considerably less (approximately $50 \%$ ).

In all experiments the results were expressed as the percentage of radiolabel recovered in each cell population in comparison with the amount of radioactivity in the applied cell population. That the total recovered was less than $100 \%$ was accounted for by (1) non-specific losses onto the tissue culture plastics and pipettes and (2) a slight reduction in counting efficiency when the cells are distributed in the larger volume of the washings. However, since the non-specific losses were in proportion to the amount recovered, accurate comparisons could be made between different migration chambers. In each experiment the results are expressed as the mean of 3-6 individual determinations. Each experiment was carried out 2-4 times with concordant results.

\section{Results}

\section{Kinetics of cell migration}

In order to examine the parameters which modulate cell migration, we applied populations of ConA activated cells to control or TNF- $\alpha$ activated endothelium, and recovered the cells at 2-24 h after application (Table I). The figures, show that $60-70 \%$ of the cells did not bind to endothelium and this is similar to the numbers which remain unbound in comparable adhesion assays. Of the remainder, a very small percentage bind to the endothelium but do not migrate across it, and are detached in cold $\mathrm{Ca}^{2+} / \mathrm{Mg}^{2+}$ free medium. Observation of the migration chambers during the assays, showed that a number of these cells were phase dark (non-viable), but there was also an appreciable number of phase bright cells bound to the endothelial surface, which were not detached by either of the two washes. Radiolabel
TABLE I

\section{THE KINETICS OF LYMPHOCYTE MIGRATION ACROSS CEREBRAL ENDOTHELIUM}

The results show the percentage of ${ }^{125} I$ recovered from each of the four compartments of the migration chambers. The value given is the mean and standard deviation of a typical experiment, using three or four identical migration chambers for each value.

\begin{tabular}{lcc}
\hline & \multicolumn{2}{c}{ Endothelium $^{\mathrm{a}}$} \\
\cline { 2 - 3 } & TNF $-\alpha$ & Control \\
\hline Migration time & \multicolumn{1}{c}{$24 \mathrm{~h}$} & $24 \mathrm{~h}$ \\
\hline Unbound cells & $73.9 \pm 2.5 \%$ & $72.9 \pm 1.0 \%$ \\
Surface bound & $1.1 \pm 0.3 \%$ & $2.7 \pm 0.6 \%$ \\
Migrating (lysate) & $2.0 \pm 0.2 \%$ & $1.5 \pm 0.3 \%$ \\
Fully migrating & $11.3 \pm 0.4 \%$ & $11.5 \pm 1.3 \%$ \\
\hline Migration time & $6 \mathrm{~h}$ & $6 \mathrm{~h}$ \\
\hline Unbound cells & $67.0 \pm 5.5 \%$ & $65.0 \pm 2.8 \%$ \\
Surface bound & $3.8 \pm 1.6 \%$ & $3.7 \pm 0.7 \%$ \\
Migrating (lysate) & $3.5 \pm 1.9 \%$ & $6.4 \pm 0.1 \%$ \\
Fully migrating & $6.3 \pm 1.2 \%$ & $6.9 \pm 0.9 \%$ \\
\hline Migration time & $2 \mathrm{~h}$ & $2 \mathrm{~h}$ \\
\hline Unbound cells & $60.1 \pm 5.5 \%$ & $70.0 \pm 5.2 \%$ \\
Surface bound & $5.4 \pm 1.3 \%$ & $2.7 \pm 0.5 \%$ \\
Migrating (lysate) & $9.9 \pm 4.4 \%$ & $7.4 \pm 0.8 \%$ \\
Fully migrating & $2.4 \pm 0.5 \%$ & $1.8 \pm 0.5 \%$ \\
\hline
\end{tabular}

a Endothelium was either untreated (control) or pulsed with $50 \mathrm{ng} / \mathrm{ml}$ TNF- $\alpha$ at $24 \mathrm{~h}$ before the start of the migration

${ }^{b}$ Cells were allowed to migrate at $37^{\circ} \mathrm{C}$ for either $2,6 \mathrm{~h}$ or 24 $h$ before recovery.

from these cells was recovered in the SDS lysate, together with label from cells which had migrated underneath the endothelium, but which had not reached the bottom of the migration chamber. Comparison of the location of the cells at 2, 6 and $24 \mathrm{~h}$ shows that there was an increase in the proportion of cells which reached the bottom of the lower chamber, but only a small increase in the numbers which had migrated through the endothelium (lysate plus lower chamber). In each case the migrating population contained 9-13\% of the recovered radioactivity, while the activity present in the lower chamber increased from $1.8 \%$ to $11.5 \%$ between 2 and $24 \mathrm{~h}$. It appeared, therefore that migration across the endothelium occurred within the first $6 \mathrm{~h}$, and that the cells from beneath the endothelium then moved down through the chambers over the next $24 \mathrm{~h}$. 
Our previous studies on lymphocyte adhesion had shown that the number of ${ }^{51} \mathrm{Cr}$-labelled adherent cells was dependent both on the state of lymphocyte activation, and on whether the endothelium had been activated by cytokines. In contrast, in the migration assay, the location and numbers of cells which migrated across the endothelium at 2, 6 and $24 \mathrm{~h}$ was not affected by cytokine activation of the endothelium. It should be reemphasized that this observation is related to the amount of ${ }^{125} \mathrm{IUdR}$ recovered in each fraction. All the lymphocytes incorporate ${ }^{125} \mathrm{IUdR}$, but it is preferentially taken up by dividing cells.

The migration system also permits comparisons of migration across cerebral and extracerebral endothelium in vitro. Fig. 1 shows a comparison of the migration of mitogen-activated lymphocytes across epididymal fat endothelium and cerebral endothelium. In this experiment the numbers of migrating cells were not significantly different after $2 \mathrm{~h}(p>0.05)$ but at $24 \mathrm{~h}$ slightly more cells had migrated across epididymal fat endothelium ( $p<0.01$; two-tailed $t$ test).

\section{Visualisation of migrating cells}

In order to visualise the phases of the migration, we prepared endothelium on cyclopore

Cerebral endothelium

\section{Epididymal fat endothelium}
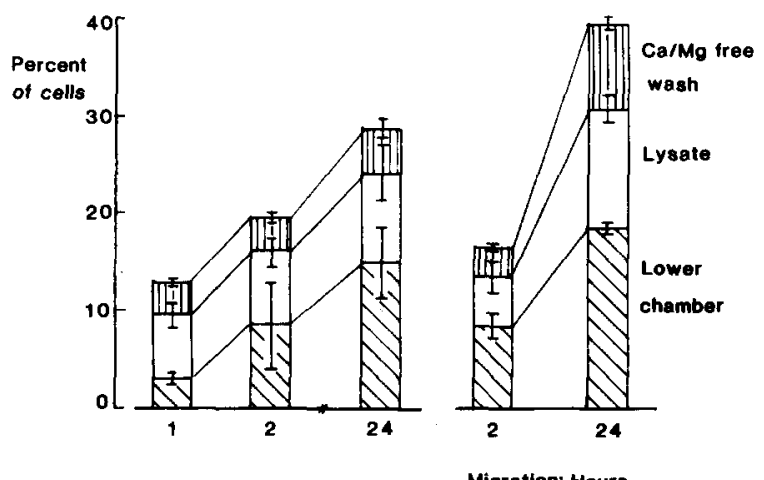

Migration: Hours

Fig. 1. Migration of lymphocytes through monolayers of brain endothelium, compared with epididymal fat endothelium at 1 , 2 and $24 \mathrm{~h}$. The bars represent accumulation of cells in each of the compartments of the migration system (excluding unbound cells). The bar length gives the mean and standard deviation for each compartment. membranes, cut in transverse section, for electron microscopy following fixation with $2 \%$ glutaraldehyde (Figs. $2 a$ and $2 b$ ). For transmission EM, it was necessary to permeate the membranes with propylene oxide/epon in four successive steps of $30 \mathrm{~min}$ each, with the ratio of propylene oxide/ epon being $4: 1,2: 1,1: 2$ and finally neat epon. In all other respects the EM procedure was standard. Scanning electron micrographs were taken above and below the endothelialised Goretex membrane (Figs. $2 c$ and $2 d$ ). Fig. $2 c$ shows lymphocytes adherent to the upper surface of the endothelial cell monolayer. The slight cracks in the monolayer were artifacts created by the differential shrinkage of the monolayer and the membrane during fixation. The view from beneath the membranes (Fig. $2 d$ ) revealed cells emerging from the Goretex/extracellular matrix and migrating down the nylon fibres which act as a support for the membrane itself. We also visualised cells emerging from the lower surface of cyclopore membranes (Fig. 2e). The large pore size of this membrane in comparison with the lymphocytes is apparent. We also looked at transverse sections of cyclopore membranes in the light microscope (not shown). It was clear from this and from the transmission EMs (Fig. 2a) that the endothelium is a single layer of cells on the upper surface of the membrane. Very rarely, we have noted that one or two endothelial cells have migrated down through the membrane and proceeded to grow on the lower surface, immediately around a pore. The transmission EM also revealed how the lymphocytes become attached to the surface of the endothelium, with pseudopodia extending under lips in the endothelium.

\section{Migration of $T$ cell subpopulations}

This system also permits analysis of the migrating populations. For example, they can be phenotyped. To determine which populations migrate across the endothelium, we applied mixed populations of unstimulated and mitogen-activated lymphocytes to the endothelium. After $24 \mathrm{~h}$, cells which had crossed the endothelium and bound to the bottom of the lower chamber were phenotyped for $\mathrm{CD} 4, \mathrm{CD} 8$ and $\mathrm{CD} 2$ by immunoperoxidase staining. The results of a typical experiment are shown in Table II. In contrast to our work on 

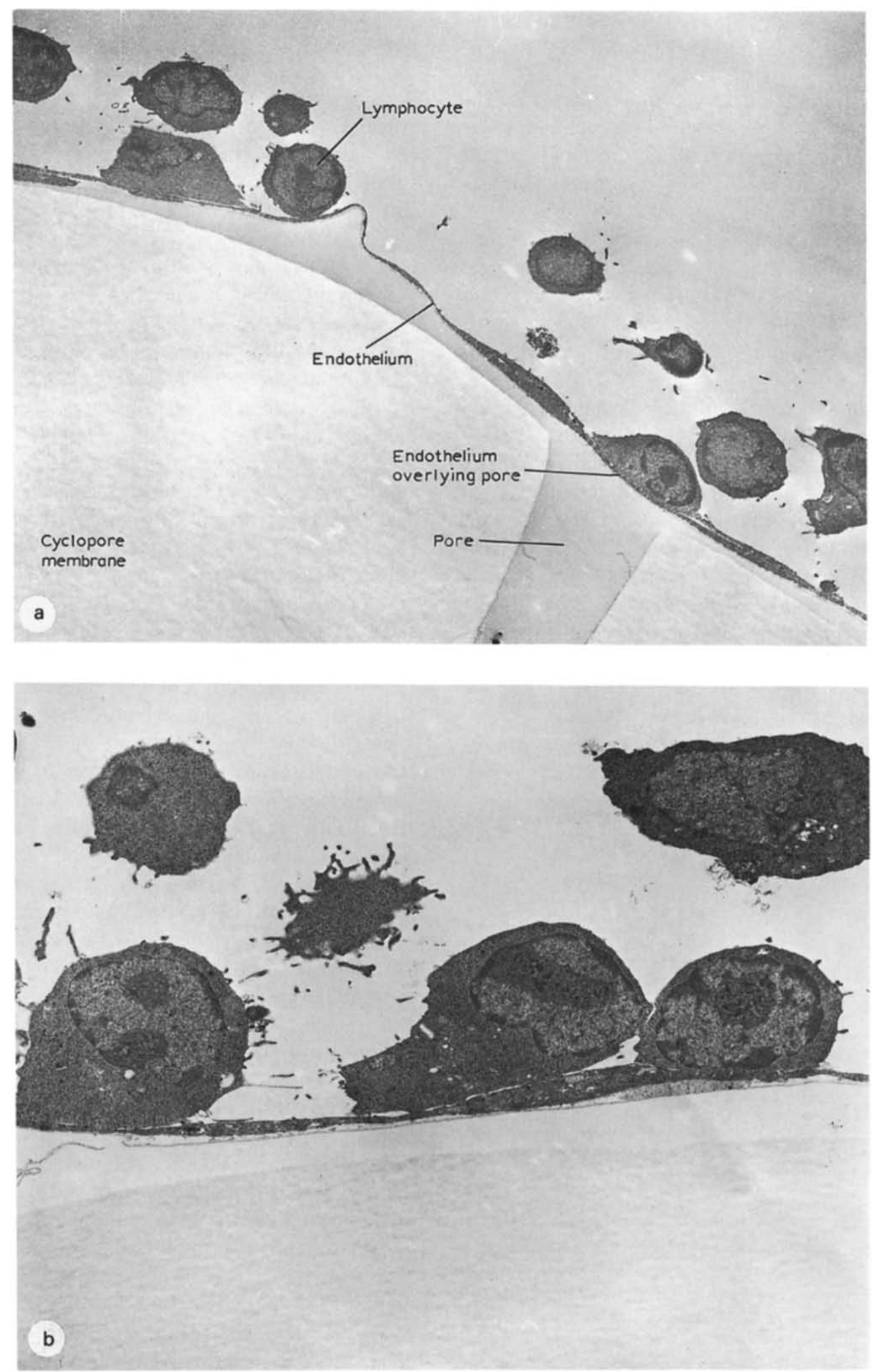

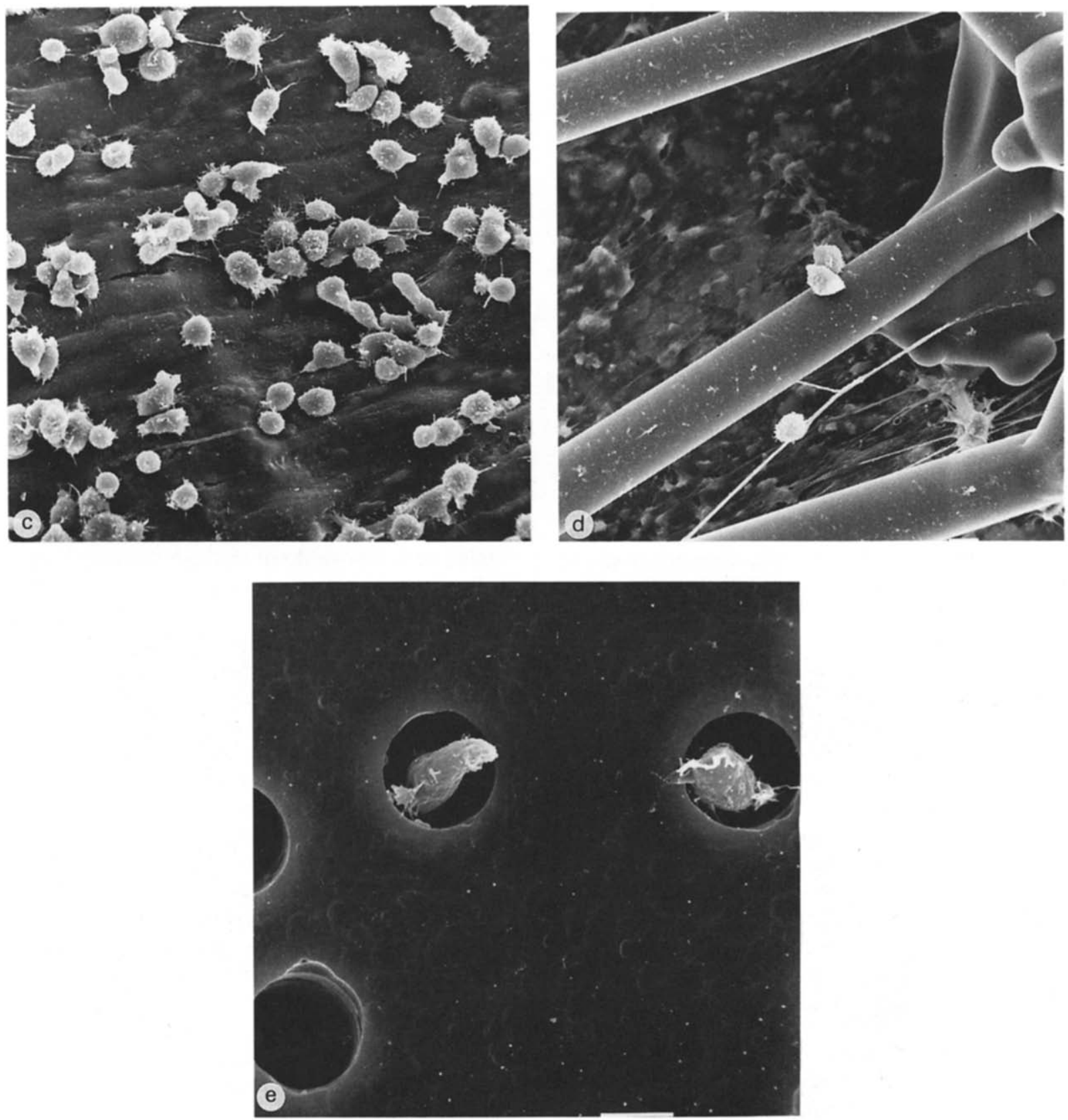

Fig. 2. Transmission EM of mitogen-activated lymphocytes attaching to the upper surface of endothelialised cyclopore membranes $(a$ and $b$ ). $a$ shows the continuity of the endothelium over a membrane pore. $b$ indicates the initial point-attachments of the migrating cells. $c$ is a scanning EM taken of the upper surface of Goretex membranes covered with brain endothelium and overlaid with ConA stimulated lymphocytes and $d$ shows a similar preparation taken at a later stage viewed from beneath the membrane with cells migrating down the nylon support fibres of the membrane. $e$ is a scanning EM of the lower surface of an endothelialised cyclopore membrane 20 min after application of lymphocytes showing the first cohort of cells to pass down through the membrane. 


\section{TABLE II}

THE MIGRATION OF $T$ CELL SUBPOPULATIONS ACROSS CEREBRAL ENDOTHELIUM

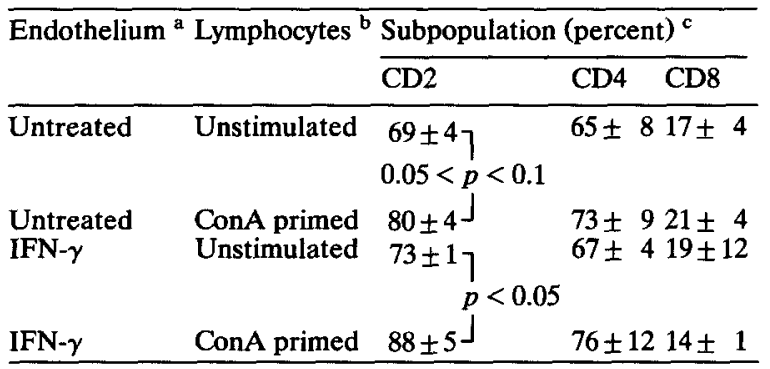

${ }^{a}$ Endothelium was either untreated or pulsed for $24 \mathrm{~h}$ with 50 $\mathrm{U} / \mathrm{ml}$ rat IFN- $\boldsymbol{\gamma}$.

${ }^{b}$ Lymphocytes were either unstimulated or primed for $16 \mathrm{~h}$ with $5 \mu \mathrm{g} / \mathrm{ml}$ ConA. The initial population applied to the endothelium contained $49 \% \mathrm{CD}^{+}$cells and $20 \% \mathrm{CD}^{+}$ cells.

c Results are expressed as the mean and standard deviation of three separate migration chambers, in which cells of each type were quantitated by counting the proportion stained by the immunoperoxidase method for the stated marker, and located at the bottom of the migration chamber.

lymphocyte adhesion, the migration assay shows that $\mathrm{CD} 4^{+}$cells cross the endothelium in greater numbers than $\mathrm{CD}^{+}$cells. The difference between these two assays suggests that although $\mathrm{CD}^{+}$cells (and $\mathrm{B}$ cells) bind efficiently to the endothelium, they are slower to move across than $\mathrm{CD} 4{ }^{+}$cells and consequently they remain on the top, accessible for antibody staining for a longer period of time. The second point of interest is the slight, but significant increase in the proportions of $\mathrm{T}$ cells $\left(\mathrm{CD}^{+}\right)$when using ConA activated cells on IFN- $\gamma$ activated endothelium. We presume that this is due to the preferential activation of $\mathrm{T}$ cells by ConA.

\section{Discussion}

The migration assay described here was based on one developed for monocyte migration across large vessel endothelium. The modifications required reflect the fastidiousness of brain endothelium in tissue culture, and their peculiar barrierrelated properties. The critical modifications may be summarised as follows: (1) the use of matrigel on the Goretex membranes to allow endothelial attachment; (2) the use of collagen overlays, to allow cell spreading; (3) the use of first passage brain endothelium-offering the retention of phenotype but resulting in an even distribution of seeded cells; and (4) a switch away from the use of ${ }^{51} \mathrm{Cr}$ for cell labelling, due to the unexpected way in which it is transported by the brain endothelium. We would also recommend use of the cyclopore membranes in preference to Goretex, since they are easier to handle, have superior properties for light microscopy, and cut without fracturing for electron microscopy.

This assay has allowed us to examine the characteristics of leukocytes which traverse the cerebral endothelium, and to differentiate the factors that affect adhesion from those controlling migration. Recent work suggests that different adhesion molecules control these two events (Oppenheimer-Marks et al., 1991). Although adhesion is self-evidently the first step in lymphocyte migration, other processes must occur before the cells can move into the brain parenchyma. These processes are less well defined but include the ability to (a) move down through the endothelial cells, (b) express enzymes which digest basement membrane proteins and (c) express surface molecules (e.g., $\beta-1$ integrins) which permit the cell to interact with components of the extracellular matrix (Hemler, 1990).

We have not carried out comprehensive kinetic studies of adhesion and migration. However, it appears that any migrating cells will have bound to the endothelium by $30 \mathrm{~min}$ (data not shown), have migrated across within $6 \mathrm{~h}$ and then gradually have made their way down through the membrane over the next $24 \mathrm{~h}$.

We have shown previously that lymphocyte activation greatly enhances their ability to bind to brain endothelium in vitro. Similarly, in vivo, during EAE it also appears that the dividing cells attach preferentially to the brain endothelium (Raine et al., 1990). Attachment of cells is greatest in the 1-2 days after activation, although our more recent studies show that the ability to migrate increases up to 8 days after activation. This may reflect the enhanced ability of the activated $T$ cells to express enzymes which degrade matrix proteins at this later stage (Naparstek et al., 1984). 
Another notable difference between the studies on adhesion and those on migration is the differential effects seen with lymphocyte subpopulations. We have shown that $\mathrm{CD}^{+} \mathrm{T}$ cells and $B$ cells bind to brain endothelium more efficiently than $\mathrm{CD}^{+}{ }^{+} \mathrm{T}$ cells (Pryce et al., 1991). However, these studies show that $\mathrm{CD} 4^{+} \mathrm{T}$ cells migrate to the base of the chambers more efficiently than $\mathrm{CD}^{+} \mathrm{T}$ cells or $\mathrm{B}$ cells. It is not possible to directly compare migration and adhesion assays since insufficient cells are available to carry out both assays simultaneously, with different lymphocyte populations. Nevertheless the $\mathrm{CD} 4{ }^{+}$cells consistently migrate better than the $\mathrm{CD}^{+}$population. At present we remain unclear about whether the difference is fundamental to the different lymphocyte populations or reflects differential activation, and the expression of adhesion molecules or enzymes.

We are not yet certain that the endothelial monolayers are fully closed to large molecules, as is the blood brain barrier in vivo. Small flaws in the monolayers or occasional contaminating cells would compromise the integrity of the barrier in vitro. Nevertheless, since lymphocytes are too large to reach the lower chamber passively, and since contact with the endothelium is necessary to initiate migration, we believe that this is a useful model for examining factors which affect leukocyte movement into the CNS.

\section{Acknowledgements}

This work was supported by a grant from the Medical Research Council of Great Britain. We are most greatful to W.L. Gore and associates for supplying us with the hydrophilic Goretex membrane used in the migration assays.

\section{References}

Bowman, P.D., Ennis, S.R., Rarey, K.E., Betz, A.L. and Goldstein, G.W. (1983) Brain microvessel endothelial cells in tissue culture: a model for study of blood brain barrier permeability. Ann. Neurol. 14, 396.

Darby, H., Brown, K.A., Anderson, R.A., Williams, B.T. and Dumonde, D.C. (1988) Transendothelial chemotaxis in vitro of human monocytes. J. Immunol. Methods 88, 133.

Hemler, M.E. (1990) VLA proteins in the integrin family: Structures, functions and their role on leukocytes. Ann. Rev. Immunol. 8, 365.

Hughes, C.C.W. and Lantos, P.L. (1986) Brain capillary endothelial cells in vitro lack surface IgG Fc receptors. Neurosci. Lett. 68, 100.

Hughes, C.C.W., Male, D.K. and Lantos, P.L. (1988) Adhesion of lymphocytes to cerebral microvascular cells: effects of interferon- $\gamma$ tumour necrosis factor and interleukin-1. Immunology 64, 677 .

Male, D. (1992) Immunology of brain endothelium and the blood brain barrier. In: M.W.B. Bradbury (Ed.), Physiology and Pharmacology of the Blood Brain Barrier. Springer Verlag, Berlin, pp. 397-415.

Male, D.K., Pryce, G. and Hughes, C.C.W. (1987) Antigen presentation in brain: $\mathrm{MHC}$ induction on brain endothelium and astrocytes compared. Immunology 60, 453 .

Male, D.K., Pryce, G., Hughes, C.C.W. and Lantos, P.L. (1990) Lymphocyte migration into brain modelled in vitro; control by lymphocyte activation cytokines and antigen. Cell. Immunol. 127, 1.

Naparstek, Y., Cohen, I.R., Fuks, Z. and Vlodavsky, I. (1984) Activated $\mathrm{T}$ lymphocytes produce a matrix degrading heparin sulphate endoglycosidase. Nature 310, 241.

Oppenheimer-Marks, N., Davis, L.S., Bogue, D.T., Ramberg, J. and Lipsky, P.E. (1991) Differential utilisation of ICAM-1 and VCAM-1 during the adhesion and transendothelial migration of human T-lymphocytes. J. Immunol. 147, 2913.

Pryce, G., Male, D.K. and Sarkar, C. (1991) Control of lymphocyte migration into brain: selective interactions of lymphocyte subpopulations with brain endothelium. Immunology $72,393$.

Raine, C.S., Cannella, B., Duijvestijn, A.M. and Cross, A.H. (1990) Homing to central nervous system vasculature by antigen-specific lymphocytes: Lymphocyte/endothelial cell adhesion during the initial stages of autoimmune demyelination. Lab. Invest. $63,476$.

Vorbrodt, A.W., Dobrogowska, D.H., Lossinsky, A.S. and Wisniewski, H.M. (1990) Changes in the distribution of anionic sites in brain micro-blood vessels with and without amyloid deposits in scrapie-infected mice. Acta Neuropathol. $79,353$.

Wekerle, H., Engelhardt, B., Risau, W. and Meyermann, K. (1991) Interactions of $T$ lymphocytes with cerebral endothelial cells in vitro. Brain Pathol. 1, 107.

Wisniewski, H.M. and Lossinsky, A.S. (1991) Structural and functional aspects of the interaction of inflammatory cells with the blood brain barrier in experimental brain inflammation. Brain Pathol. 1, 89. 